\title{
The Chemistry of the Cell Walls of rod Mutants of Bacillus subtilis
}

\author{
By H. J. ROGERS, MOYRA MCCONNELL AND R. C. HUGHES \\ National Institute for Medical Research, Mill Hill, London N.W.7
}

(Accepted for publication 7 April I97I)

SUMMARY

The walls of two rod mutants of Bacillus subtilis $\mathrm{I} 68 \mathrm{trp}$ and of the parent grown under the same conditions were identical in qualitative composition, with the possible exception of rod-5 grown on minimal medium without added sodium chloride; these walls did not contain galactosamine. The amounts of $\alpha, \epsilon$-diaminopimelic acid and glutamic acid in the walls of the mutants were lowered by growth on minimal media supplemented by $0.8 \mathrm{M}$-sodium chloride, whereas in the parent these growth conditions led to increases in the contents of these two amino acids. The mucopeptide of mutant rod-4 was very little cross-linked when growing under conditions that lead to a round form, but this also applied to the mucopeptide of the parent grown under the same conditions. When the mutant grew as a rod, its mucopeptide again had the same degree of cross-linking as that of the parent grown in rich media. The concentration of organic phosphorus in the walls of the mutants, presumed to be present as teichoic acid, was about the same as that in the parent and was unaffected by the growth conditions. Thus the chemistry of the walls of rod mutants did not provide obvious evidence of expression of the genetic lesion.

\section{INTRODUCTION}

The isolation and characterization of two classes of rod mutants from a strain of Bacillus subtilis and of one class from two strains of $B$. licheniformis have been described (Rogers, McConnell \& Burdett, 1968, I970; Rogers \& McConnell, I970). These mutants grow as chains or groups of round forms on minimal media or on these media supplemented by low concentrations of casein hydrolysate. On these minimal media solidified with agar and supplemented by high concentrations of $\mathrm{NaCl}$ or $\mathrm{KCl}$, one class (A) grows as rods. This class also grows as rods on nutrient agar or on the minimal media supplemented by higher concentrations of casein hydrolysate. The second class (B) is only transformed to rods by very rich media containing yeast extract. The component of the casein hydrolysate essential for enabling the class A mutant to grow as rods is L-glutamic acid, or its immediate metabolic products (Rogers \& McConnell, 1970). High salt content of liquid minimal media is important in effecting the morphological transformation principally by allowing much lower concentrations of glutamic acid to be effective. Probably L-glutamine formed from L-glutamic acid and ammonium ions, rather than the amino acid itself, is the metabolic intermediate essential for the mutant to grow as rods. A temperature-sensitive rod mutant, also of B. subtilis 168 , with identical morphology, has been isolated (Boylan \& Mendelson, 1969; Cole, Popkin, Boylan \& Mendelson, 1970). This mutant grows as a rod at $30^{\circ}$ and as a round form at $45^{\circ}$. At the restrictive temperature it is reported to have less teichoic acid in its wall.

We have now examined the chemistry of the walls of one rod mutant of class A (Rogers 
et al. 1970) and, in a preliminary fashion, one of class B, comparing these with the parent strain grown under conditions such that the class A mutant grew either as a round form or as a rod.

\section{METHODS}

Micro-organisms. The parent strain was Bacillus subtilis 168 trp. The mutants were rod-4 and rod-5 (Rogers \& McConnell, 1970; Rogers et al. 1970). The former is of class A and the latter of class B. They were maintained and subcultured as previously described.

Media and growth of micro-organisms. The following media were used: (a) liquid minimal medium (Rogers et al. 1970) containing tryptophan (100 $\mu \mathrm{g} . / \mathrm{ml}$.); (b) the same medium supplemented with $0 . \mathrm{I} \%$ of acid hydrolysed casein (Difco); $(c)$ medium $(b)$ supplemented with $0.8 \mathrm{M}-\mathrm{NaCl} ;(d)$ medium (a) supplemented with $0.5 \%$ of acid hydrolysed casein instead of $0.1 \% ;(e)$ an acid hydrolysed casein $(\mathrm{I} \% \mathrm{w} / \mathrm{v})$ salts medium $(\mathrm{CH} / \mathrm{S} / \mathrm{C})(\mathrm{Janczura}$, Perkins \& Rogers, I960), supplemented by tryptophan (100 $\mu \mathrm{g} . / \mathrm{ml}$.). Spizizen's salts medium was as described by Spizizen (1958).

The cultures were all grown in Ehrlenmeyer flasks, I/5 filled, aerated by shaking, for $24 \mathrm{~h}$. at $35^{\circ}$. When grown in medium (a), an inoculum was used (Rogers et al. 1970) such that growth was in the early exponential phase within $24 \mathrm{~h}$. For the analytical work in which the general composition of the walls was established, the bacteria were grown on the solidified minimal medium with tryptophan ( $100 \mu \mathrm{g} . / \mathrm{ml}$.) and $0.1 \%$ of acid hydrolysed casein added (previously described by Rogers et al. (1970) and called here SA medium), and on this medium supplemented by $0.8 \mathrm{M}-\mathrm{NaCl}$. The solidified media in Roux bottles were inoculated with a suspension made from single colonies from an overnight culture grown on the same medium. After 2 days at $35^{\circ}$ the bacteria were washed from the agar with a $2 \%(w / v)$ sodium dodecyl sulphate solution to inactivate lytic enzymes, broken, and the walls prepared. When walls were required for subsequent autolysis experiments, the sodium dodecyl sulphate treatment was omitted.

Preparation of walls. This procedure was as previously described under 'cell walls for autolysis' (Rogers et al. 1970).

Autolysis of walls. Walls were autolysed by suspending them at a density of 2 to $3 \mathrm{mg}$. $/ \mathrm{ml}$. in $0.02 \mathrm{M}$-ammonium carbonate buffer, $\mathrm{pH} 8.6$, and incubating the suspensions for $\mathrm{I} 8 \mathrm{~h}$. at $35^{\circ}$.

Dimensions of micro-organisms. A drop of an exponentially growing culture was mixed with a drop of dilute formalin and added to a drop of molten $2 \%(w / v)$ clear agar on a slide, and a coverslip placed over the mixture. When the agar had set solid, the lengths of 20 organisms selected at random were measured with a Watson image-shearing eyepiece (W. Watson \& Sons Ltd, Barnet, Hertfordshire) using a phase-contrast microscope and a magnification of $\times 900$.

\section{Chromatographic methods}

$D E A E$-cellulose and Sephadex G-25 columns were used according to methods previously described (Hughes, Pavlik, Rogers \& Tanner, 1968; Hughes, 1970).

Paper. One- and two-dimensional paper chromatograms were run in the following solvents: (A) butan-I-ol + pyridine + water (6:4:3, by vol.); (B) butan-I-ol + acetic + acid water (63:10:27, by vol.); (C) isobutyric acid $+0.5 \mathrm{M}-\mathrm{NH}_{4} \mathrm{OH}$ (5:3, by vol.); (D) $n$-propanol + aqueous ammonia (S.G. 0.88 dil. $/ 500)\left(17: 3\right.$, by vol.). The papers were dried at $40^{\circ}$ and dipped or sprayed with $0.5 \%(\mathrm{w} / \mathrm{v})$ ninhydrin in butan-I-ol for amino acids, or aniline hydrogen phthalate (Baar, 1954) for sugars, or the Elson-Morgan reagent (Partridge, 1948) for amino sugars. 


\section{Analytical methods}

Free amino groups. Free amino groups of peptides and amino acids in fractions from eluates from columns were determined by reaction with ninhydrin (Rosen, 1957). The $\mathrm{N}$-terminal and $\epsilon$-amino groups of $\alpha, \epsilon$-diaminopimelic acid were determined by reaction with fluorodinitrobenzene (Hughes, I968a).

Carbohydrate. The anthrone reagent was used according to the method of Dreywood (I946), to detect hexose in the effluent samples from columns. A standard solution of glucose was used for comparison.

Phosphorus. This was determined by the method of Allen (1940), after hydrolysis of the wall samples in $6 \mathrm{~N}-\mathrm{HCl}$ for $\mathrm{I} 8 \mathrm{~h}$. at $105^{\circ}$.

Amino acids. These were determined either by quantitative paper chromatography, using the ninhydrin reaction, or in the Technicon amino acid analyser. Our thanks are due to $\mathrm{Dr} \mathrm{S}$. Jacobs of this Institute for these determinations. The required hydrolysates were made as follows: 2 to $3 \mathrm{mg}$. of dried cell wall was heated at $105^{\circ}$ for $\mathrm{I} 6 \mathrm{~h}$. with $\mathrm{I} \cdot 0 \mathrm{ml}$. of $6 \mathrm{~N}-\mathrm{HCl}$ in a sealed ampoule, or samples $(0 . \mathrm{I}$ to $0.25 \mathrm{ml}$ ) containing peptides ( $0 . \mathrm{I}$ to $0.6 \mu$ mole diaminopimelate) were heated with equal volumes of $12 \mathrm{~N}-\mathrm{HCl}$ as above. The hydrolysate was then evaporated to dryness in vacuo and the residue was dissolved in $1 \cdot 0 \mathrm{ml}$. of water. The solution was again evaporated to dryness in vacuo. This was repeated once to remove residual $\mathrm{HCl}$. Finally the residue was dissolved in $0.6 \mathrm{ml}$. of water for analysis by paper chromatography. When the cell walls were to be analysed using the Technicon amino acid analyser, the hydrolysates were first filtered to remove any insoluble material, then evaporated to dryness in vacuo. The residue was dissolved in 5 or $10 \mathrm{ml}$. of $0.2 \mathrm{M}$-sodium citrate buffer, $\mathrm{pH} 2 \cdot 2$, containing $2 \%(\mathrm{w} / \mathrm{v})$ thiodiglycol.

2,6-Diaminopimelic acid in hydrolysates of whole organisms. Parent and mutant bacteria were grown on SA medium with and without the addition of $0.8 \mathrm{M}-\mathrm{NaCl}$. After 2 days incubation at $35^{\circ}$, organisms were washed off the agar, washed twice with water at $0^{\circ}$ and freeze-dried. To $6 \mathrm{mg}$. of dried organisms was added $5 \mathrm{ml}$. of $10 \%(\mathrm{w} / \mathrm{v})$ trichloroacetic acid and the suspension was kept at $0^{\circ}$ for $2 \mathrm{~h}$. The residue was washed three times with water and hydrolysed with $\mathrm{I} \mathrm{ml}$. of $6 \mathrm{~N}-\mathrm{HCl}$ for $\mathrm{I} 6 \mathrm{~h}$. at $105^{\circ}$. Bacteria were also grown in the liquid minimal media $(b)$ and $(c)$ and rod-4 was grown as a round form in medium $(a)$. When growth reached the late exponential phase, the organisms were centrifuged at $10,000 \mathrm{rev}$./ min. and treated as above. The hydrolysates were treated as before for analysis on the Technicon amino acid analyser. Again our thanks are due to Dr S. Jacobs for these determinations and for modifications necessary to allow clear resolution of the diaminopimelic acid peak.

Amino sugars. The galactosamine and glucosamine were separately determined as peak areas on the Technicon analyser, in the same $6 \mathrm{~N}$-acid hydrolysates as used for amino acid analysis. A more accurate determination of muramic acid which minimized acid destruction was made by hydrolysing 2 to $3 \mathrm{mg}$. of each wall with $4 \mathrm{~N}-\mathrm{HCl}$ for $4 \mathrm{~h}$. at $100^{\circ}$. The glucosamine-galactosamine fraction and the muramic acid were then separated and estimated by the method described by Hughes (1968a).

\section{Analysis of wall preparations}

RESULTS

Table I shows the analysis of the acid hydrolysates of walls from the parent and mutant micro-organisms grown on SA medium for 2 days at $35^{\circ}$ in the presence and absence of $0.8 \mathrm{M}-\mathrm{NaCl}$. On the medium without added salt, the two mutants were growing as round 
苾论

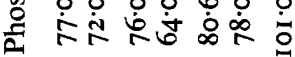

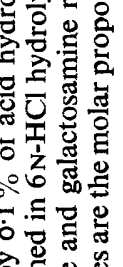


forms, whereas rod-4 was growing as a rod on the medium with $0.8 \mathrm{M} \mathrm{NaCl}$. The parent, of course, grew as a rod on both media, and rod-5 belonging to class B (Rogers et al. 1970) grew as a round form on both media. Apart from the amino acids and amino sugars shown in Table I, no significant amounts of other substances reacting with ninhydrin were seen either in the tracings from the column effluents or on two-dimensional paper chromatograms of the acid hydrolysates. Of the carbohydrates, only glucose in addition to glucosamine, galactosamine and muramic acid was detected in two-dimensional paper chromatograms of the walls hydrolysed for $4 \mathrm{~h}$. with $4 \mathrm{~N}-\mathrm{HCl}$ and stained by the Elson-Morgan reagents, or for $2 \mathrm{~h}$. with $2 \mathrm{~N}-\mathrm{HCl}$ at $105^{\circ}$ and stained with aniline phthalate. The 2,6-diaminopimelic acid, glutamic acid, muramic acid and glucosamine belong exclusively to the mucopeptide, whilst the phosphorus, glucose and galactosamine can be removed in the teichoic acid fraction (Young, I966a, 1967; Hughes \& Tanner, I968; Hughes et al. 1968). The alanine is partly from the mucopeptide and partly from the teichoic acid; in the latter it is presumably linked by ester bonds to the glycerol or glucose (Archibald \& Baddiley, 1966). Small differences appeared in the molar ratios of the constituents but none consistently distinguished the mutants. The reduction in the amount of alanine in the walls of both the parent and mutants grown in the presence of high concentrations of $\mathrm{NaCl}$ is presumably due to the presence of less ester-linked alanine in the walls (Heptinstall, Archibald \& Baddiley, 197I).

The concentrations ( $\mu$ moles/100 mg. of wall) of the mucopeptide constituents (2,6-diaminopimelic acid and glutamic acid) were higher in the walls of the parent strain grown in the presence of $0.8 \mathrm{M}-\mathrm{NaCl}$, whereas the mutants showed the reverse effect (Table I). The concentrations of muramic acid appeared to be somewhat less affected by the presence of additional salt in the growth medium, but again showed the same trend as the amino acids. The galactosamine content of the walls was increased both in the mutants and the parent by growth in the $0.8 \mathrm{M}-\mathrm{NaCl}$ medium. None was detected in the walls of rod-5 grown in the absence of added salt. The phosphorus content of the walls of either the mutants or the parents was only very slightly altered, whether growing in the unsupplemented minimal medium or in the presence of $0.8 \mathrm{M}-\mathrm{NaCl}$. This indicates that the teichoic acid content of the walls remained relatively constant. The total weight of the walls accounted for by the analyses was 50 to $60 \%$, assuming that the phosphorus was part of a normal glycerol teichoic acid. This was lower than the recoveries obtained in some other work with bacilli (Hughes et al. 1968), but no other constituents of the walls could be found. Ash determinations were not done.

\section{The amount of mucopeptide in the rod mutant}

In sections examined with the electron microscope many of the round rod-4 mutant organisms appeared to have very thick walls (Rogers et al. 1970) and when growing in the rod form the poles were often thickened. In this work the organisms were grown on the surface of agar media. To see whether these pictures corresponded to the presence in the mutant of more mucopeptide per unit mass of micro-organism than in the parent strain, attempts were first made to estimate the amount of whole wall by direct measurement of the weight of wall isolated from a given weight of micro-organisms. This proved difficult to carry out reproducibly, even when the lytic enzymes were rapidly inactivated by the addition of sodium dodecyl sulphate, despite the fact that the amount of wall material had been estimated satisfactorily in staphylococci by this direct method some years ago (Mandelstam \& Rogers, 1959). Instead, the amount of 2,6-diaminopimelic acid was estimated in hydrolysates of whole organisms that had first been twice extracted for $\mathrm{I} h$. at 0 to $4^{\circ}$ with $10 \%$ $(w / v)$ trichloroacetic acid to remove from the bacteria any soluble precursor containing the 
amino acid. Then, from the previous analyses (Table I) it was possible to calculate the amount of total wall material in the mutants as compared with that in the parent strain. After growth on solid SA medium in the absence of added sodium chloride, the amounts of mucopeptide in the mutants and in the parent were very high, as indicated by the estimations of $\alpha, \epsilon$-diaminopimelic acid in hydrolysates of the whole organisms (Table 2). There is a correspondingly large amount of wall material calculated from the analyses in Table $\mathrm{I}$. The $0.8 \mathrm{M}-\mathrm{NaCl}$ added to the agar media lowers the amounts to values more normally found in bacilli. However, both the large amount of mucopeptide and these effects of added $\mathrm{NaCl}$ seem to be a result of growth on the surface of solidified media, rather than significant for the morphological change in the mutant. When grown in liquid media, both the mutants and the parent had about normal amounts of diaminopimelic acid, and hence presumably of mucopeptide, per unit weight of micro-organisms (Table 2). As far as the mutants are concerned, this chemical difference between bacteria grown in liquid and those from the surface of agar media would confirm the impression gained from electron microscopy that in liquid media the walls of the mutants are more uniform and less thick than are those from agar (unpublished work).

\section{Table 2. Amount of wall per unit weight of parent and mutant bacteria from Bacillus subtilis 168 trp}

The minimal media were the salts-glucose- $0.1 \%$ casein hydrolysate medium solidified with agar (SA) (Rogers et al. 1970) and the fluid media (a), (b) or (c) of the Methods section of this paper. Values for the content of $\alpha, \epsilon$-diaminopimelic acid (DAP) in the walls are from the results quoted in Table I; values for bacteria grown in liquid media are not available.

\begin{tabular}{|c|c|c|c|c|c|}
\hline Strain & Growth medium & Shape & $\begin{array}{l}\% \text { DAP in } \\
\text { organism }\end{array}$ & $\begin{array}{l}\% \text { DAP in } \\
\text { wall }\end{array}$ & $\%$ Wall \\
\hline \multirow[t]{2}{*}{$\operatorname{rod}-4$} & $\begin{array}{r}\text { Minimal (SA) } \\
(a)\end{array}$ & $\begin{array}{l}\text { Round } \\
\text { Round }\end{array}$ & $\begin{array}{l}3.60 \\
2.09\end{array}$ & 9.40 & $38 \cdot 30$ \\
\hline & $\begin{array}{r}+0.8 \mathrm{M}-\mathrm{NaCl}(\mathrm{SA}) \\
(c)\end{array}$ & $\begin{array}{l}\text { Rod } \\
\text { Rod }\end{array}$ & $\begin{array}{l}1 \cdot 90 \\
2 \cdot 15\end{array}$ & $\underline{6.40}$ & $29 \cdot 60$ \\
\hline \multirow[t]{2}{*}{ rod-5 } & $\begin{array}{r}\text { Minimal (SA) } \\
(b)\end{array}$ & $\begin{array}{l}\text { Round } \\
\text { Round }\end{array}$ & $\begin{array}{l}2 \cdot 70 \\
1 \cdot 94\end{array}$ & $\frac{7 \cdot 60}{-}$ & $\underline{35 \cdot 50}$ \\
\hline & $\begin{array}{r}+0.8 \mathrm{M} \mathrm{NaCl}(\mathrm{SA}) \\
(c)\end{array}$ & $\begin{array}{l}\text { Round } \\
\text { Round }\end{array}$ & $\begin{array}{l}1 \cdot 04 \\
1 \cdot 68\end{array}$ & $\stackrel{5 \cdot 00}{-}$ & $\stackrel{20 \cdot 80}{-}$ \\
\hline \multirow[t]{2}{*}{ Parent } & $\begin{array}{c}\text { Minimal (SA) } \\
\text { (b) }\end{array}$ & $\begin{array}{l}\text { Rod } \\
\text { Rod }\end{array}$ & $\begin{array}{l}2 \cdot 80 \\
2 \cdot 10\end{array}$ & $\underset{7 \cdot 10}{-}$ & $39 \cdot 40$ \\
\hline & $+0.8 \mathrm{M} \mathrm{NaCl}(\mathrm{SA})$ & Rod & $I \cdot 68$ & 9.01 & I $8 \cdot 7$ \\
\hline
\end{tabular}

\section{Fine structure of the mucopeptide}

Degree of cross-linking. A high proportion of the mucopeptide of bacilli is made up of polysaccharide chains of $N$-acetylglucosamine and $N$-acetylmuramic acid joined together by $\mathrm{I} \rightarrow 4 \beta$ bonds which are cross-linked by the heptapeptide L-ala.D-glu.meso-DAP.Dala.meso-DAP.D-glu.L-ala (Hughes, I968 b; Hughes et al. 1968; Mirelman \& Sharon, I968; Warth \& Strominger, 1969). Also attached to the polysaccharide is an approximately equimolar amount of the uncrosslinked tripeptide L-ala.D-glu .meso-DAP (see Fig. I). This structure differs from that described for Escherichia coli by the absence of terminal carboxylD-alanyl residues. Details of the structural work on bacterial mucopeptides are summarized elsewhere (Rogers \& Perkins, 1968; Ghuysen, 1968).

The next experiments are designed to see whether the degree of cross-linking between the 
peptides is the same in the mutant and parent bacteria, and to see whether the presence of high salt concentration or higher amounts of acid hydrolysed casein affect this.

The most satisfactory way to determine the degree of cross-linking in Bacillus subtilis is to allow the natural autolysin to act, since this enzyme hydrolyses the bonds between the muramyl carboxyl group and the amino group of L-alanine (Young, I966 $b$; see Fig. I). The degree of cross-linking can then be estimated from the relative proportions of heptaand tripeptides in the autolysate. The walls of the parent liberate on autolysis 75 to $80 \%$ of their peptide as a mixture of tripeptides and heptapeptides (Hughes et al. 1968; Hughes, 1970). The molar ratio of these peptides in B. licheniformis and B. subtilis, growing exponentially in a casein hydrolysate medium, is close to $\mathrm{I} \cdot 2: \mathrm{I} \cdot \mathrm{O}$ (Hughes et al. 1968; Hughes, 1970).

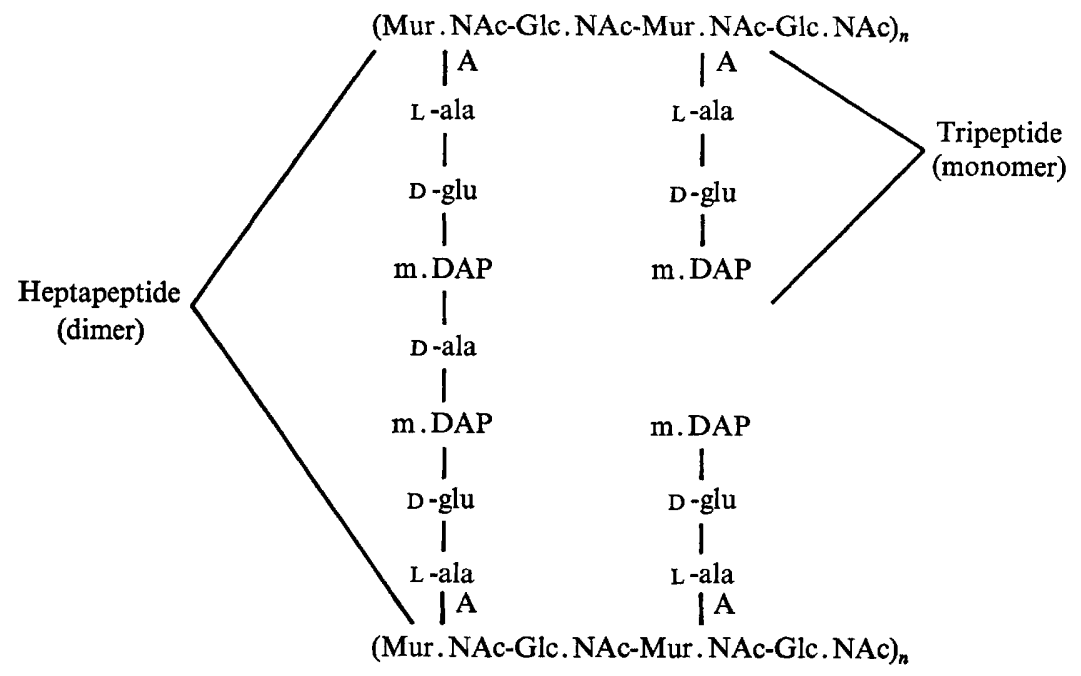

Fig. I. Structure of the mucopeptide present in the walls of several bacilli including Bacillus subtilis I68. The bond marked A between the carboxyl group of muramic acid and the amino group of L-alanine is that which is split by the major autolysin present in the walls.

Accordingly, rod-4 was grown in media $(a),(b),(c),(d)$ and $(e)$ (see Methods) and rod-5 in medium $(b)$. The walls were prepared and then allowed to autolyse in $0.02 \mathrm{M}$-ammonium carbonate buffer at $\mathrm{pH} 8.6$ at $35^{\circ}$. Autolysis went to completion in $\mathrm{I} 8 \mathrm{~h}$., except in the case of the walls isolated from bacteria, whether parent or mutant strains, grown in the presence of $0.8 \mathrm{M}-\mathrm{NaCl}$. These failed to dissolve completely. This failure was shown to be due not to a difference in the wall structure but to relatively little of the relevant active autolysin being in the walls. When a partially purified autolysin of the same specificity isolated from Bacillus licheniformis 6346 (J. S. Thompson \& H. J. Rogers, unpublished work) was allowed to act on the walls from organisms grown in the high salt media under the same conditions, they dissolved completely and at about the same rate as walls prepared from the parent grown without added $\mathrm{NaCl}$. The autolysates, or the enzymic hydrolysates with walls from cells grown in the presence of $0.8 \mathrm{M}-\mathrm{NaCl}$, were then dried, freed of the ammonium carbonate buffer by evaporation in vacuo, and redissolved in water before being passed down a DEAE-cellulose column. The peptides freed from hexosamine and other materials were eluted (as a single peak) from the column with a gradient of pyridine acetate buffer at $\mathrm{pH}$ 5. I. The elution profiles obtained were similar to those of Hughes (1970). Three fractions were eluted after the peptides. These were a fraction (A2 of Hughes, 1970) containing all the 
constituents of mucopeptide; the mucopeptide glycan virtually free of peptide (A 3 of Hughes, 1970); the teichoic acid (A4 of Hughes, 1970).

The tubes containing peptides alone were pooled, dried, freed of buffer by evaporation in vacuo, dissolved in water and analysed in one or both of two different ways. (I) They were placed on filter paper and, after running in solvent $C$ (see Methods) alongside suitable markers of authentic monomer (tripeptide) and dimer (heptapeptide) from the parent strain, the areas containing the monomer and dimer were cut out, eluted with water, the eluate dried and the residue hydrolysed with hydrochloric acid. The amounts of 2,6-diaminopimelic acid contained in them were then estimated, thus defining the amount of monomer and dimer present in 60 to $70 \%$ of the original autolysates. (2) The peptides present were analysed on a size basis, using columns of Sephadex G-25. The fractions in the peaks obtained from these columns were pooled, the pools dried and the material they contained examined as before by paper chromatography.

\section{Table 3. The monomer and dimer content of autolysates of walls from rod-4 and rod-5 mutants from Bacillus subtilis 168 trp}

The media were as described in Methods. The numbers given under 'monomer' are the numbers of moles related to $\mathrm{I} \cdot 0$ mole of dimer. The methods for the separation and estimation of monomers and dimers are given in the text.

$\begin{array}{lclccc}\begin{array}{c}\text { Micro- } \\ \text { organism }\end{array} & \begin{array}{c}\text { Growth } \\ \text { medium }\end{array} & \text { Shape } & \text { Monomer } & \text { Dimer } & \begin{array}{c}\text { of 2,6-diamino- } \\ \text { pimelic acid } \\ (\%)\end{array} \\ \text { rod-4 } & \text { (a) } & \text { Round } & \text { all } & 0 & 67 \\ & \text { (b) } & \text { Round } & 4 \cdot 0 & \mathbf{I} \cdot 0 & 72 \\ & \text { (c) } & \text { Rod } & 2 \cdot 10 & \mathbf{I} \cdot 0 & 72 \\ \text { rod-5 } & \text { (d) } & \text { Rod } & \mathbf{I} \cdot 54 & \mathbf{I} \cdot 0 & 62 \\ \text { Parent } & \text { (b) } & \text { Round } & \mathbf{I} \cdot 36 & \mathbf{I} \cdot 0 & - \\ & \text { (a) } & \text { Rod } & \text { all } & 0 & 57 \\ & \text { (e) } & \text { Rod } & 1 \cdot 2 & \mathbf{I} \cdot 0 & 75\end{array}$

Table 3 summarizes the results obtained for the mutants grown under different conditions. The apparent degree of cross-linking of the mucopeptide in the walls of rod-4 depended upon the conditions for growth of the mutant. When grown on minimal medium it grew exclusively as round forms and the autolysate of the mucopeptide showed no evidence for the presence of dimers; in other words there was no evidence of cross-linking in about $70 \%$ of the total peptides. When grown in the medium supplemented with $0.1 \%$ of acid hydrolysed casein, there was about one molecule of the dimer compared with four of the monomer in the fraction of the autolysate examined. Under these latter conditions of growth, although the culture is entirely made of round forms after $18 \mathrm{~h}$., the early stages of growth involve the formation of short filaments which subsequently give rise to round forms (Rogers \& McConnell, 1970). In this same medium, supplemented further by $0.8 \mathrm{M}-\mathrm{NaCl}$, the organisms were rods after $24 \mathrm{~h}$. growth at $35^{\circ}$ and the degree of cross-linking increased still further, although not yet as extensive as in the medium containing $0.5 \%$ casein hydrolysate, where the ratio of peptide monomer to dimer in the walls was nearly the same as that previously obtained (Hughes et al. 1968; Hughes, 1970) for the parent strain growing in I \% casein hydrolysate medium.

The walls of the parent strain were then examined by the same technique, after the 
organisms had been grown under some of the conditions that were used for the mutant. Similar changes were found. No dimers were found among the peptides separated from the walls of the parent after it had been grown in the minimal medium, and it thus behaved exactly like the mutant.

These observations raised two problems. If no dimers could be found, how did the mucopeptide in the walls of organisms grown in minimal medium hold together? If the degree of cross-linking of the mucopeptide plays any part in the morphology of the mutant, why did the parent also apparently have such a low degree of cross-linking when grown in minimal medium? One possible answer to the first problem lies with the 25 to $30 \%$ of peptide which does not appear in the main peptide from the DEAE-cellulose column. This material (A 2 above) was that which contained a small amount of all the mucopeptide

\title{
Table 4. Dimensions of individual organisms of Bacillus subtilis I68 trp grown in different media
}

\begin{abstract}
All the cultures were $50 \mathrm{ml}$. volumes in $250 \mathrm{ml}$. side-arm flasks. The micro-organisms were subcultured in the media until the growth rate was constant. The dimensions were then also found to be constant. The mean dimensions are given \pm the variance.
\end{abstract}

\begin{tabular}{|c|c|c|c|}
\hline \multirow[b]{2}{*}{ Growth medium } & \multirow[b]{2}{*}{$\begin{array}{c}\text { Doubling } \\
\text { time } \\
\text { (min.) }\end{array}$} & \multicolumn{2}{|c|}{ Dimensions } \\
\hline & & $\begin{array}{c}\text { Length } \\
(\mu \mathrm{m} .)\end{array}$ & $\begin{array}{l}\text { Diameter } \\
\quad(\mu \mathrm{m} .)\end{array}$ \\
\hline Minimal salts & 70 & $2 \cdot 34 \pm 0.35$ & - \\
\hline Spizizen's salts & 50 & $2 \cdot 87 \pm 0.40$ & $0.811 \pm 0.002$ \\
\hline Casein hydrolysate & 36 & $4 \cdot 13 \pm 0.30$ & $0.75 \pm 0.001$ \\
\hline Penassay broth (i)* & - & $9 \cdot 26 \pm 2 \cdot 70$ & - \\
\hline (Difco) (ii)* & 24 & $5 \cdot 29 \pm 0.79$ & - \\
\hline
\end{tabular}

* These measurements were from two separate experiments in which the lengths were measured in the exponential phase of growth of a primary batch culture inoculated from an overnight culture of the microorganisms. These cultures are not as near steady state as the others.

constituents. Treatment of A2 derived from rod-4 grown in medium ( $a$ ) with fluorodinitrobenzene showed that about half ( $45 \%$ ) of its $\epsilon$-amino groups of diaminopimelic acid were cross-linked, more than that obtained in the same fraction from the walls of the parent grown in minimal medium ( $25 \%$ ) and less than in walls of the parent grown in $\mathrm{r} \%$ casein hydrolysate medium ( 60 to $70 \%$ ), but presumably enough to hold the walls together.

At this stage of the work no clear answer is possible to the second problem above, but an interesting correlation has been noticed. The size of rod-shaped Gram-negative bacteria is known to be related to their rate of growth (Schaechter, Maaløe \& Kjeldegaard, 1958). The results from preliminary experiments in which the dimensions of Bacillus subtilis 168 trp growing exponentially in various media were measured are shown in Table 4. The length of the individual organisms was much influenced by the nature of the medium in which they had been growing, and was directly related to the exponential growth rate. Possibly the very low degree of cross-linking of the mucopeptide present in the wall preparations from both the parent and the mutant strains, when grown in minimal salts media, is related to the presence of more septal material per unit weight of organisms in the relatively short organisms than in the longer ones from rich media.

Length of the polysaccharide chains. The glycan chains of the mucopeptide, made of I $\rightarrow 4 \beta$-linked residues of $N$-acetylglucosamine and $N$-acetylmuramic acid have an average length of Io hexosamine units in mucopeptide from Bacillus subtilis I68 trp (Hughes, 1970). The length of these chains was examined in rod-4 grown in medium $(b)$. The reduction of 
glycan fractions with sodium borohydride to measure the number of free-reducing ends and the use of $\beta$ - $N$-acetylglucosaminidase to measure the number of non-reducing ends of the glycan strands has been described (Hughes, 1970). The average lengths of the chains in the mutant measured by either method was the same (10 hexosamine units) as those in the parent, irrespective of the growth conditions used.

\section{DISCUSSION}

The work described shows that there is very little difference between the walls of the rod-4 mutant and those of the parent after they have been grown under identical conditions. The walls of the mutant, grown as round forms, contain a high proportion of uncrosslinked mucopeptide compared with those from organisms grown as rods. This was thought to be a very satisfactory explanation (Rogers, 1969) for the morphology, since poorly crosslinked mucopeptide would be expected to be a great deal less rigid than the more fully crosslinked polymer. However, the mucopeptide of the walls of the parent grown under the same conditions as those used for the mutant also shows the same apparent lack of crosslinking, despite the consistent growth of the parent as a rod, albeit a very short rod. Thus although the low degree of cross-linking may be a necessary condition for the round morphology in rod-4, it cannot be the cause of the difference between parent and mutant. It would seem reasonable to suspect that the decreased amount of crosslinking in the mucopeptide from the parent grown in minimal medium is related to the increased proportion of 'end material' in the very short rods formed by the parent growing in this medium compared with those from richer media. In a sense the round form of the mutant consists of all ends with no rod-like middle, together with much incomplete septal material (Rogers et al. 1970). The essential difference between parent and mutant can then be looked upon as some lesion in the mechanism whereby the rod normally extends. This then might be related to the regulation of the rate of mucopeptide synthesis relative to other cell constituents or to the location of its formation. The only slight evidence obtained for a difference in behaviour between the mutants and the parent is in the effect of the presence of $0.8 \mathrm{M}-\mathrm{NaCl}$ in the growth medium on the proportion of mucopeptide in the walls. In the mutants this is decreased whereas in the parent it is slightly increased. Changes, however, in the proportion of the polymers in walls are fairly common under the stimulus of nutritional changes, and considerably more work would be required before its relation to the morphological change could be established. Moreover, the rod-5 mutant, which does not change its morphology when grown in media containing $0.8 \mathrm{M}-\mathrm{NaCl}$, also shows the same change as rod-4, which does change. This latter point may not completely rule out the significance in the changes in chemistry since indirect evidence may suggest that the class B mutants, of which rod-5 is a member, may have more than a single genetic defect, whereas present evidence supports class $\mathrm{A}$ as being simple mutants (unpublished work).

Both the round and rod form of rod-4 have about the same concentration of organic phosphorus in the walls. No evidence was therefore found for a great reduction in the amount of teichoic acid in the round form, as has been claimed for the temperaturesensitive rod mutant growing above its restrictive temperature (Cole et al. 1970). Also, the chain lengths of the glycan part of the mucopeptide were the same in the round form and the parent. Thus there was no evidence for this sort of difference such as previously reported for Arthrobacter crystallopoietes (Krulwich, Ensign, Tipper \& Strominger, 1967a,b). This organism has longer glycan chains when growing as a rod than when growing as a sphere.

In view of these rather discouraging results, which gave little support to the possibility 
that the rod mutation would be expressed in the chemistry of the wall, it might be more reasonable to favour a hypothesis that looks to the location or regulation of sites on the membrane where wall biosynthesis occurs. In this respect the absence of mesosomes from the mutant (Cole et al. 1970; Rogers et al. 1970) might well be relevant because of their involvement in septation of bacilli (Rogers, 1970).

\section{REFERENCES}

Allen, R. J. L. (1940). The estimation of phosphorus. Biochemical Journal 34, 858-865.

Archibald, A. R. \& Baddiley, J. (1966). The teichoic acids. Advances in Carbohydrate Chemistry 21, 323375 .

BAAR, S. (1954). Quantitative estimations of glucose by partition chromatography. Biochemical Journal 58, I 75-176.

Boylan, R. J. \& MENdelson, N. H. (I969). Initial characterization of a temperature-sensitive rod-mutant of Bacillus subtilis. Journal of Bacteriology xoo, 1316-1321.

Cole, R. M., Popkin, T. J., Boylan, R. J. \& Mendelson, N. H. (1970). Ultrastructure of a temperaturesensitive rod-mutant of Bacillus subtilis. Journal of Bacteriology 103, 793-8 10.

Dreywood, R. (1946). Qualitative test for carbohydrate material. Industrial and Engineering Chemistry (analytical edition) $\mathbf{r 8 ,} 499$.

GHUYSEN, J. M. (I968). Use of bacteriolytic enzymes in determination of wall structure and their role in cell metabolism. Bacteriological Reviews 32, 425-464.

Heprinstall, S., ARchibald, A. R. \& Baddiley, J. (197I). Teichoic acids and membrane function in bacteria. Nature, London 225, 519-52I.

Hughes, R. C. (1968a). The cell wall of Bacillus licheniformis NCTC 6346. Composition of the mucopeptide component. Biochemical Journal ro6, 4I-48.

Hughes, R. C. (1968b). The cell wall of Bacillus licheniformis NCTC 6346. Isolation of low molecular weight fragments from the soluble mucopeptide. Biochemical Journal ro6, 49-59.

Hughes, R. C. (1970). Autolysis of isolated cell walls of Bacillus licheniformis NCTC 6346 and Bacillus subtilis Marburg strain 168. Biochemical Journal II9, 849-860.

Hughes, R. C., Pavlik, J. G., Rogers, H. J. \& TANner, P. J. (I968). Organization of polymers in the cell walls of some bacilli. Nature, London 219, 642-644.

Hughes, R. C. \& TANner, P. J. (1968). The action of dilute alkali on bacterial cell walls. Biochemical and Biophysical Research Communications 33, 22-27.

Janczura, E., Perkins, H. R. \& Rogers, H. J. (I960). Teichuronic acid: a mucopolysaccharide present in cell wall preparations from vegetative cells of Bacillus subtilis. Biochemical Journal 8o, 82-93.

Krulwich, T. A., Ensign, J. C., TipPer, D. J. \& Strominger, J. L. (1967a). Sphere-rod morphogenesis in Arthrobacter crystallopoietes. I. Cell wall composition and polysaccharides of the peptidoglycan. Journal of Bacteriology 94, 734-740.

Krulwich, T. A., Ensign, J. C., Tipper, D. J. \& Strominger, J. L. (1967b). Sphere-rod morphogenesis in Arthrobacter crystallopoietes. II. Peptides of the cell wall peptidoglycan. Journal of Bacteriology 94, 74I-750.

Mandelstam, J. \& Rogers, H. J. (1959). The incorporation of amino acids into cell-wall mucopeptide of staphylococci and the effect of antibiotics on the process. Biochemical Journal 72, 654-662.

Mirelman, D. \& SHARON, N. (I968). Isolation and characterization of the disaccharide $N$-acetylglucosaminyl$\beta$-(I $\rightarrow 4$ - $N$-acetylmuramic acid and two tripeptide derivatives of this disaccharide from lysozyme digests of Bacillus licheniformis ATCC 9945 cell walls. Journal of Biological Chemistry 243, 2279-2287.

PARTRIDGE, S. M. (I948). Filter-paper partition chromatography of sugars. Biochemical Journal 42, $238-242$.

RoGERS, H. J. (1969). The organization of polymers in Gram-positive and Gram-negative bacteria. Journal of General Microbiology 57, iv.

Rogers, H. J. (1970). Bacterial growth and the cell envelope. Bacteriological Reviews 34, I94-214.

Rogers, H. J. \& Perkins, H. R. (I968). Cell Walls and Membranes. London: E. \& F. N. Spon.

Rogers, H. J., MCCONNell, M. \& BurdetT, I. D. J. (1968). Cell-wall or membrane mutants of Bacillus subtilis and Bacillus licheniformis with grossly deformed morphology. Nature, London 219, 285-288.

Rogers, H. J., MCCONNELl, M. \& BuRdeTt, I. D. J. (I970). The isolation and characterization of mutants of Bacillus subtilis and Bacillus licheniformis with disturbed morphology and cell division. Journal of General Microbiology 6r, 155-17r. 
Rogers, H. J. \& MCCONNELL, M. (1970). The role of L-glutamine in the phenotypic change of a rod mutant derived from Bacillus subtilis 168. Journal of General Microbiology 6r, 173-181.

Rosen, H. (1957). A modified ninhydrin colorimetric analysis for amino acids. Archives of Biochemistry and Biophysics 67, 10-15.

Schaechter, M., MaAløe, O. \& KJeldegaARd, N. O. (1958). Dependency on medium and temperature of cell size, and chemical composition during balanced growth of Salmonella typhimurium. Journal of General Microbiology 19, 592-606.

SPIZIZEN, J. (1958). Transformation of biochemically deficient strains of Bacillus subtilis by DNA. Proceedings of the National Academy of Sciences of the United States of America 44, 1072.

WARTH, A. D. \& STrominger, J. L. (1969). Structure of the peptidoglycan of bacterial spores: occurrence of the lactam of muramic acid. Proceedings of the National Academy of Sciences of the United States of America 64, 528-535.

YounG, F. E. (1966a). Fractionation and partial characterization of the products of autolysis of cell walls of Bacillus subtilis. Journal of Bacteriology 92, 839-846.

Young, F. E. (1966 b). Autolytic enzyme associated with cell walls of Bacillus subtilis. Journal of Biological Chemistry 241, 3462-3467.

Young, F. E. (1967). Requirement of glucosylated teichoic acid for adsorption of phage in Bacillus subtilis I68. Proceedings of the National Academy of Sciences of the United States of America 58, 2377-2384. 